\title{
A Strategic Approach to Polmtical Risk Assessment
}

\author{
Daniel Sauers \\ Lincoln University \\ Canterbury, New Zealand
}

Recent events in the Middle East, where the outbreak of hostilities has put foreign investments in jeopardy, and the political volatility in Eastem Europe, Asia, and Latin America, once again point to the need for the systematic assessment and management of political risks associated with oversea investments. While a number of sophisticated techniques for assessing political risk are available, most multinational corporations (MNCs) use subjective, sporadic analysis by overseas staff and independent consultants [21]. Furthermore, the integration of political risk assessments into the strategic decision-making process of MNCs tends to be informal and unsystematic [8].

Political risk has long been identified as a prime factor to consider when making foreign investment decisions. However, it has only been in the past decade that political risk assessment has emerged as an established managerial function in MNCs. As with any new function, a number of problems have emerged. In an in-depth study of ten United States-based MNCs, Mascarenhas and Atherton [9] found a general lack of satisfaction on the part of executives with regard to their existing system of assessing political risk. The need for a more formal assessment of political risk and its implications for strategic decision-making is apparent.

In this article, a general framework for integrating political risk assessment into the strategic planning process of the MNC is developed. The political risk assessment approaches of American firms who first established joint ventures in China and the Soviet Union are then evaluated in light of this framework.

\section{Political Risk Assessment and Strategic Management}

There is a basic linkage between political risk assessment and strategic management. Higgins defines strategic management as "the process of managing the pursuit of organizational mission while managing the relationship of the organization to its environment" [5, p. 3]. The primary purpose of strategic management is to optimize the "fit" between the organization and its present and future environment. Micallef, on the other hand, refers to political risk assessment as "the systematic means of assessing and managing the political risks of foreign direct investment or international business" [10, p. 47]. While political risk assessment should play an integral part in a MNC's strategic planning process, in practice, its role is often limited to political forecasting [10]. As for the integration of political assessments into decision making, most authors confine themselves to the capital budgeting process where forecasts are used to adjust cash flows or the discount rate [6]. Capital budgeting is but one function that can and should be affected by political risk judgements. A strategic approach to political risk assessment is required in order to fully integrate this function into the corporate planning process. 
A strategic approach to political risk assessment involves four interrelated steps:

1. Identification and analysis of key political issues and trends.

2. Development of policy, strategy, and tactics for addressing key issues.

3. Implementation and execution of the chosen strategic plan.

4. Evaluation and adjustment of the strategic plan in light of actual experience andchanging political conditions.

A model of the strategic approach to political risk assessment is presented in Figure 1. Phase $I$ involves the application of environmental scanning and forecasting techniques to identify and analyze potential political risks. Phase 2 involves the evaluation of feasible alternatives and the development of a strategic plan which takes into consideration political risk factors. Phase 3 embraces all the administrative actions associated with putting a strategic plan into action and making it work as well as political developments permit. Phase 4, evaluation and adjustment, is both the end and the beginning of the political risk assessment process. The march of political change guarantees that the time will come for making revisions in strategy. Most of the time, revisions will be of the fine-tuning variety, but occasions for major overhaul in strategy arise-sometimes because of significant political developments.

Figure 1: Strategic Political Risk Assessment

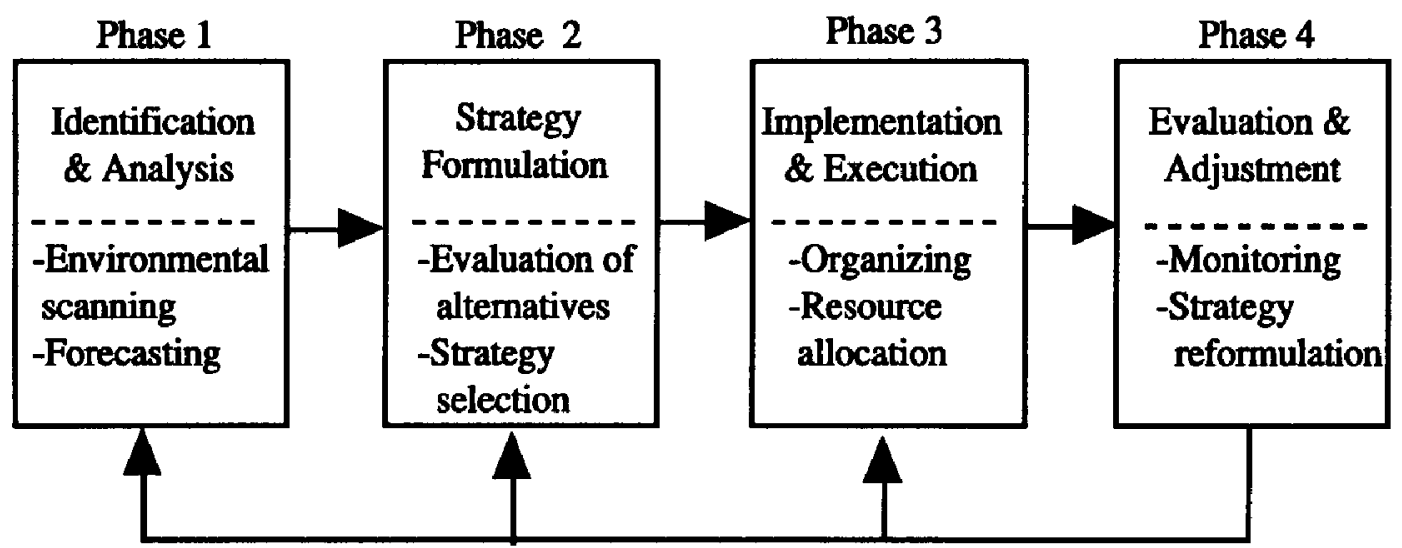

Before examining each of the phases in the political risk assessment process in more detail, a word of caution: it is practically impossible to construct a model of political risk assessment which accurately portrays the dynamic, interactive nature of the process. While the model indicates four sequential phases, this is only partially realistic. The relationship between issue identification and analysis, and strategy formulation is particularly troublesome to portray realistically. In order to focus scanning efforts, for example, it is often advisable for management to start the process by tentatively defining the firm's strategy [9]. This scenario highlights the fact that the component phases of the political risk assessment process are interactive and can occur simultaneously. 


\section{Phase One Issue Identification and Risk Analysis}

Schmidt [17] stresses the importance of understanding what constitutes a political risk. Only after political risks have been defined or identified can international managers posit relationships, gauge risk exposure, and recommend a course of action aimed at capitalizing, alleviating, or avoiding the various forms of this risk.

Although the term "political risk" is used extensively in the international business literature, there is little agreement regarding the precise meaning of the term. In developing an operational definition of political risk suitable for integration into the strategic planning process of the MNC, it is helpful to consider the concept in an environmental context. Robock [15], for example, suggests that political risk in international business exists when discontinuities, which are difficult to anticipate, occur in the business environment as a result of political change. These changes in the business environment constitute a risk if they have the potential for significantly affecting the profit or other goals of a particular enterprise. Robock notes that fluctuations in the political environment that do not change the business environment of the firm significantly do not constitute a political risk. Thus, what is a political risk for one firm may not be a political risk for another.

It is also helpful to distinguish between uncertainty and risk in the political environment. Political uncertainty describes an unmeasured, subjective doubt about a political environment. Political risk, on the other hand, denotes a relatively objective measurement, usually resulting in a probability estimate of that doubt. Root writes: "When the international manager makes a probability judgement of an uncertain political event in a host country, he thereby converts a political uncertainty into a political risk" $[16$, p. 57]. Political risk-assessment provides a means for the objective evaluation of foreign investment climates by converting uncertainties in the political environment into probability terms.

Finally, risk that is of a political nature encompasses governmental actions as well as any environmental forces which could change the government or its policies. Thus, political risk generally refers to a full range of environmental factors that may affect a firm's performance in a particular country. Normal business risks that emanate from pure market developments, however, are excluded from this definition.

Such a comprehensive view of political risk stresses the importance of environmental scanning in identifying potential sources of political risk. Scanning activities should have as their focus the identification of the key political issues. Such issues represent the major opportunities and threats which could critically affect the firm's performance in a particular country. A key political issue may be immediate or emerging, host country, home country, international or global in origin, that will directly or indirectly affect any facet of the firm's operations [21].

Unfortunately, several problems plague political data collection efforts ([9], [18]). Pertinent data is often not readily available. First-hand data collection of a political nature is not only difficult and time-consuming but also likely to be biased as the local people respond guardedly to sensitive questioning. Data that are available tend to be biased and not in a readily usable format. Information may be distorted due to internal 
politics, and by communication problems arising from differences in personal orientation and from the peculiar nature of political data. Finally, data that is collected for political risk assessment is often irrelevant.

Sethi and Luther [18] place an emphasis on collecting data that are strategyspecific. This can be accomplished by tentatively defining the initial strategy so that relevant information can be determined in the scanning process. Several sources of data can also be employed to cross-check information for biases [9]. Incorporating these suggestions before initiating the scanning process should eliminate many of the problems noted above.

Once data on the environment has been collected, it must be analyzed and interpreted in an effort to forecast future issues and problems. There are a number of sophisticated qualitative and quantitatively oriented techniques available for this purpose. No one technique, however, is accurate for all political forecasting situations. Political risk forecasting must be approached from the viewpoint of the individual firm. Purchasing general reports from or utilizing the services of organizations such as the Business Environmental Risk Index (BERI) or governmental agencies is useful, but such practices will be inadequate unless supported by detailed interpretation with respect to the individual firm. A firm would be well advised to follow Rice and Mahmoud's [14] seven step managerial procedure when selecting a political risk forecasting technique suitable for their needs and budget. Steps included in the procedure are: problem definition; identification of the lead time; identification of the data pattern; accuracy of the method; cost analysis; subjective and environmental factors involved in the choice and implementation of a technique.

\section{Phase Two: Strategy Formulation}

Once the key political issues have been identified and the trends forecasted, the focus of the assessment shifts to developing strategies designed to mitigate or avoid the effects of negative factors as well as take advantage of positive ones. Numerous risk management strategies have been espoused in the literature ([2], [10], [13], [15], [19]). Political risk management strategies can be employed at both the pre-investment stage and in the course of operations.

At the pre-investment stage, for example, Shapiro [19] identifies four separate, though not necessarily mutually exclusive, strategies that a MNC can follow: avoidance, political risk insurance, negotiating a concession agreement with the host government, and structuring the investment to minimize its exposure to political risk. At this stage, all feasible alternatives should be identified and evaluated with regard to risk, cost, timing, etc. For example, political risk insurance can provide partial protection against such political risks as expropriation, civil or foreign war damage, and currency inconvertibility, but premiums can run high and coverage is usually limited to $90 \%$ of equity participation [2].

Once a foreign investment is operationalized, a number of creative conflict-management strategies can be employed to cope with political risk [4]. Poynter suggests that more effective strategies are aimed at increasing the firm's bargaining power relative 
to the host government, which is "based on the scarce and significant resources the firm can make available to the host nation" [13, p. 267]. For example, a firm may increase its bargaining power by up-grading product and process technology, developing new products, increasing exports and intrafirm trade, and providing better management. Whatever strategy adopted, it should follow logically from previous analysis, addressing the key problems/issues identified and analyzed.

\section{Phase Three: Implementation and Execution}

Once the course of action has been charted, attention then shifts to the task of converting the chosen, strategic plan into actions and positive results. It is often easier to develop a sound strategic plan than it is to "make it happen." MNCs often devote a great deal of time to analyzing the environment and formulating strategies, but then fail to plan adequately for implementation. Although the basic approach to successful strategy implementation is the same for both foreign and domestic operations, specific issues and their solutions are often different because of a different set of influencing environmental factors. There are a number of conflicts that can lead to implementation problems. Phatak [12] notes that the basic cause of most problems encountered by international managers can often be traced to conflicts between the basic values held by two or more groups of people. For example, cultural differences with regard to individualism, informality, materialism, time orientation, and authority may influence a MNC's ability to implement a strategy successfully. To help alleviate strategy implementation problems an international expert, or, even better, a specialist on the specific country involved, is often needed. This person can often pinpoint likely implementation problems and suggest ways to reduce them.

\section{Phase Four: Evaluation and Adjustment}

The last major step in the strategic political risk assessment process involves the evaluation and, if necessary, the adjustment of the firm's strategy in light of changing political, social, and economic conditions. After the strategic plan is implemented, management must recognize that periodic adjustments to the plan may be necessary. Management must ensure that the strategies employed to control political risk factors are working. This requires that the MNC develop an intelligence system to monitor and evaluate political developments. According to Micallef [10], the two primary concerns here are: first, the development of reliable in-house expertise; second, insuring that the necessary information is distributed to all relevant parties. Simmon [20] provides guidelines for MNCs interested in developing their own in-house monitoring capability, which he refers to as an "Early Warning System." Feedback from those units monitoring the political environment is an integral part of the political risk assessment process, leading to revisions in political forecasts and, if necessary, corporate policy and strategy. 


\section{Organizational Integration of the Process}

The problems that plague the political risk assessment effort in MNCs can be traced to the failure to fully integrate this function into the corporate planning and decisionmaking processes. The strategic approach to political risk assessment outlined above provides a general framework for the integration of this function into the strategic planning process. How the political risk assessment function is carried out, however, can and must vary from one institutional setting to another. The specific procedures used must suit the organization, fitting what has been called the "corporate culture," or risk being ineffective no matter how accurate the assessment. While each corporation will want to develop its own particular procedures, the chances for the successful implementation of the political assessment function may be enhanced by taking into consideration some of the factors discussed below.

For optimal results, the political risk assessment function must be completely integrated into the organization's culture, structure, and strategic planning system. The process described in this paper can be operationalized through the setting up of a political risk assessment unit. Kobrin [7] argues most convincingly for the institutionalization of political risk assessment. He sttesses that environmental scanning and communication flows can be improved through the introduction of a political risk assessment unit.

The support of top management for the political risk assessment function is essential. Their role is to encourage communication with respect to political developments between line managers and staff analysts. Resistance by the corporate culture can be overcome by encouraging full participation in the political risk assessment process at all levels of the organization. Line management involvement in the assessment process can be encouraged by having line managers perform some of the assessment activities. Simmon [20] suggests a division of tasks between corporate headquarters and overseas affiliates, with the former responsible for macro risk analysis, and the latter performing micro risk assessments. Line managers, however, will usually need training to develop their assessment skills. Thus, the political specialists must also play an educational role within the firm.

Structure can be built into the system with the use of questionnaire survey reports to be completed by affiliates and assessed by headquarters [20]. A formal, systematic, uniform procedure incorporating the use of objective data should be developed. At the same time, however, ritualized, routinized, procedure-driven approaches that lead to a lack of flexibility must be avoided. In turbulent environmental conditions, going through the process is often more important than the final product.

From a strategic standpoint, the political risk assessment process must be proactive, not reactive. The common reactive stance seems to occur because assessment resources are limited and therefore used sparingly [9]. One solution would be to marshall all the resources necessary for assessing initial investments, but make this first group of resources self-liquidating, leaving only a modest group to orchestrate updates and adjustments. Furthermore, while political risk forecasters must obviously evaluate historical conditions and results, they must avoid merely extrapolating from the past. 
A forward looking perspective is particularly important when developing a strategic plan in complex and turbulent political environments.

Finally, strategic decision makers should maintain a skeptical (but not cynical) attitude toward political risk forecasts, particularly when experience is limited. On the other hand, over-reliance on quantitative data and long-term forecasts by political analysts should be avoided. Judgement should be used and forecasts limited to the time horizon dictated by the nature of the investment. Political uncertainty makes forecasting for longer time horizons an exercise in futility.

\section{Political Risk Assessment: Theory versus Practice}

In 1985, Daniels, Krug, and Nigh [3] published a study of the political risk assessment approaches used by eleven American firms who were early entrants into joint ventures in China. This study and a more recent study by Nigh and Smith [11] of the assessment approaches used by nine American companies who were among the first to enter joint ventures in the Soviet Union provide an unusual opportunity to compare practice with theory. How do the political risk assessment approaches of these two groups of American firms compare to the strategic approach set forth above? Below, some of the significant differences are addressed.

The approach to political risk assessment used by these pioneering American firms can best be described as informal and unstructured. Neither study found evidence of the application of an institutionalized assessment function utilizing structured, systematic analytical methods. Rather the approach used in most of the companies surveyed involved intuitive judgements of the political risk, made by the CEO or another executive with country responsibility or, less frequently, by headquarters staff.

In general, the firms surveyed did not report employing individuals whose primary responsibility was to analyze political conditions in foreign countries. Two firms did report having a strategic analyst at headquarters for whom political risk assessment was a part-time responsibility ([3], [11]). Another firm employed one full-time individual in the international division to collect information on political factors [3]. In another firm, government affairs personnel were responsible for political risk assessment [11].

The political risk assessments concerning the joint ventures were seldom integrated in any formal way with economic and other considerations involved in the establishment of the joint ventures. In general, they were integrated implicitly by an individual or considered in discussions among executives as they attempted to form subjective opinions on the extent of the political risk associated with their joint ventures. One firm did report that it used the assessment to shorten the payback period and increase the return on investment criterion [11].

In setting up their joint ventures, each firm reported using some method to reduce their vulnerability to political risk. These included insuring through the Overseas Private Investment Corporation (OPIC), making small initial investments, and negotiating provisions in the joint venture agreement for the United States partner's withdrawal under certain political conditions. Firms having larger investments tended to structure their financing packages so as to shift the risk to the lenders. Once the joint ventures became 
operational, however, few of the firms continued to monitor political risk.

These findings concerning the political risk assessment approaches of American firms operating joint ventures in China and the Soviet Union are consistent with the findings of an earlier Conference Board study which found that a formal political risk assessment function is still very much in the beginning stages of development in the vast majority of United States firms [4]. In general, a formal, systematic, and objective integration of assessments of political factors into the strategic decision-making process appears to be the exception rather than the rule.

\section{Conclusion}

Political risk assessment is still in its infancy. While there are numerous articles discussing sophisticated political risk assessment techniques, most of these techniques do not appear to be widely used. In addiction, integration of the assessment function into decision-making tends to be informal and unsystematic. The need for more formal assessment of political risk and its implication for corporate decision making is apparent. The process described in this article provides a general framework which can help management better integrate the political risk assessment function into its strategic planning process. With more strategic assessment systems, there is less likelihood that a firm will be deterred from investing overseas by misperceptions of the actual political risk associated with its specific investment.

\section{References}

1. Blank, S., Basek, J., Korbin, S.J, and LaPalombara, J. Assessing the Political Environment: An Emerging Function in International Companies. New York: The Conference Board, Inc. (1980).

2. Buckley, A. "Taking Account of Political Risk." Accountancy, Vol. 100, No. 1127 (July 1987), pp. 79-81.

3. Daniels, J.D., King, J. and Nigh, D. "U.S. Joint Ventures in China: Motivation and Management of Political Risk." California Management Review, Vol. XXVII, No. 4 (Summer 1985), pp. 26-58.

4. Gladwin, T.N. and Walter, I. Multinationals Under Fire: Lessons in the Management of Conflicts. New York: John Wiley (1980).

5. Higgins, J. Organizational Policy and Strategic Management: Text and Cases. Second edition. Chicago: The Dryden Press (1983).

6. Kobrin, S.J. "Political Risk: A Review and Reconsideration," Journal of International Business Sudies, Vol. 10, No. 1 (Spring/Summer 1979), pp. 67-80. 
7. Kobrin, S.J. Managing Political Risk Assessment: Strategic Response to Environmental Challenge. Los Angeles: University of California Press (1982).

8. Kobrin, S.J., Basek, J., Blank, S. and La Palombara, J. "The Assessment and Evaluation of Non-Economic Environments by American Firms: A Preliminary Report." Journal of Intemational Business Studies, Vol. 11, No. 1 (Spring/Summer 1980), pp. 32-47.

9. Mascarenhas, B. and Atherton, C. "Problems in Political Risk Assessment." Management International Review, Vol. 23, No. 2 (1983), pp. 22-32.

10. Micallef, J.V. "Political Risk Assessment." Columbia Joumal of World Business, Vol. 16, No. 2 (Summer 1981), pp. 47-52.

11. Nigh, D. and Smith, K.D. "The New US Joint Ventures in the USSR: Assessment and Management of Political Risk." Columbia Journal of World Business, Vol. 24, No. 2 (Summer 1989), pp. 39-44.

12. Phatak, A. International Dimensions of Management. Boston: Kent (1983).

13. Poynter, T.A. “Strategic Responses to Govemment Intervention in Developing Countries.” In: T.L. Brewer (ed.), Political Risks in Intemational Business, New York: Praeger (1985), pp. 259-274.

14. Rice, G. and Mahmoud, E. "A Managerial Procedure for Political Risk Forecasting." Management International Review, Vol. 26, No. 4 (1986), pp. 12-21.

15. Robock, S.H. "Political Risk: Identification and Assessment." Columbia Joumal of World Business, Vol. 6, No. 4 (July-August 1971), pp. 6-20.

16. Root, F.R. “Analyzing Political Risk in International Business.” In A. Kappor and P.D. Grub (eds.) The Multinational Enterprise in Transition: Selected Readings and Essays. Princeton: The Darwin Press (1972), pp. 354-365.

17. Schmidt, D.A. “Analyzing Political Risk." Business Horizons, Vol. 29, No. 4 (JulyAugust 1986), pp. 43-50.

18. Sethi, S.P. and Luther, K.A.N. "Political Risk Analysis and Direct Foreign Investment: Some Problems of Definition and Measurement." California Management Review, Vol. 28, No. 2 (Winter 1986), pp. 57-68.

19. Shapiro, A.C. "Managing Political Risk: A Policy Approach." Columbia Journal of World Business, Vol. 16. No. 3 (Fall 1981), pp. 63-69.

20. Simmon, J.D. "Political Risk Assessment: Past Trends and Future Prospects." Columbia Journal of World Business, Vol. 17, No. 3 (Fall 1982), pp. 62-71.

21. Simmon, J.D. "A Theoretical Perspective on Political Risk." Journal of International Business Studies, Vol. 15, No. 3 (Winter 1984), pp. 123-143. 